\title{
Antiadhesive Activity of Polysaccharide-Rich Fractions from Lithothamnion muelleri
}

\author{
Cristiane M. Soares ${ }^{\mathrm{a}}$, Bruna G. Malagoli ${ }^{\mathrm{a}}$, Gustavo B. Menezes ${ }^{\mathrm{b}}$, Vanessa Pinho $^{\mathrm{b}}$,
} Danielle G. Souza ${ }^{c}$, Mauro M. Teixeira ${ }^{\mathrm{d}}$, and Fernão C. Braga ${ }^{\mathrm{a}, *}$

a Department of Pharmaceutical Products, Faculty of Pharmacy, Universidade Federal de Minas Gerais, Belo Horizonte, Brazil. Fax: +55 31 34096935. E-mail: fernao@netuno.lcc.ufmg.br

b Department of Morphology, Institute of Biological Sciences, Universidade Federal de Minas Gerais, Belo Horizonte, Brazil

c Department of Microbiology, Institute of Biological Sciences, Universidade Federal de Minas Gerais, Belo Horizonte, Brazil

d Department of Biochemistry and Immunology, Institute of Biological Sciences, Universidade Federal de Minas Gerais, Belo Horizonte, Brazil

* Author for correspondence and reprint requests

Z. Naturforsch. 67c, 391 -397 (2012); received August 12, 2011/April 10, 2012

Red seaweeds are known sources of polysaccharides, some of which possess antiadhesive properties by inhibition of P-selectin-mediated leukocyte rolling. We here report the chemical composition and the antiadhesive activity of polysaccharide-rich fractions from the red alga Lithothamnion muelleri (Hapalidiaceae). The crude fractions enriched in polysaccharides $\mathrm{B} 1$ and $\mathrm{B} 2$ were obtained, respectively, by sequential extraction with $1 \%$ and $2 \%(\mathrm{w} / \mathrm{v}) \mathrm{Na}_{2} \mathrm{CO}_{3}$ solution, at $60{ }^{\circ} \mathrm{C}$. Fractionation of $\mathrm{B} 1$ and $\mathrm{B} 2$ by gel permeation chromatography afforded three polysaccharide-rich fractions each, whose compositions were characterized by chemical analysis (total contents of carbohydrates, proteins, sulfate, and uronic acid); their molecular weights were estimated by high-performance gel permeation chromatography (HPGPC). The antiadhesive activity of B1-derived fractions was assayed by visualizing lipopolysaccharides-induced leukocyte rolling under intravital miscroscopy. The intravenous injection of fractions B1a and B1b in mice, at the dose of $10 \mathrm{mg} / \mathrm{kg}$ body weight, reduced leukocyte rolling by approximately $90 \%$; fucoidan $(10 \mathrm{mg} / \mathrm{kg}$ body weight $)$ employed as positive control induced a similar response. Therefore, the sulfated polysaccharides of L. muelleri deserve further evaluation as potential templates for the development of new anti-inflammatory agents.

Key words: Lithothamnion muelleri, Sulfated Polysaccharides, Leukocyte Rolling Inhibition

\section{Introduction}

Sulfated galactans are considered the main constituents of the intercellular matrix and nonfibrillar cell walls of red seaweeds (Navarro et al., 2011). Among the red algae, species of the order Corallinales produce considerable lower amounts of polysaccharides in view of the strong calcified cover (Bilan and Usov, 2001). This feature probably explains the limited number of studies on polysaccharides from Lithothamnion species (Navarro et al., 2011).

Preparations containing Lithothamnion spp. are commercialized as food supplements in different countries, as sources of calcium and other minerals. Recent publications have addressed the biological effects of mineral-rich extracts of
L. calcareum including the anti-inflammatory activity on colon (Aslam et al., 2010a) and cortical glial-enriched cell cultures (Ryan et al., 2011), protective effect against $\mathrm{CCl}_{4}$-induced liver injury (Hong et al., 2011), preservation of bone structure and function (Aslam et al., 2010b), activity against $\mathrm{Ca}^{2+}$-sensitive and -resistant human colon carcinoma cells (Aslam et al., 2009), induction of differentiation in human colon tissue and modulation of stromal function (Dame et al., 2011). According to the authors, the above-mentioned activities might be related to the mineral composition of the preparations.

Numerous studies have shown that leukocyte recruitment is a multi-step cascade, which initiates with tethering of these cells onto the endothelial surface. This first contact is mediated 
by selectins (P-, E-, and L-selectin). During the inflammatory response, different stimuli, including lipopolysaccharides (LPS), thrombin, and chemokines, stimulate endothelial cells to express P-selectin (CD62P), which can also be stored inside the endothelial cells. The best-characterized ligand for the three selectins is P-selectin glycoprotein ligand-1 (PSGL-1), which is a mucin-type glycoprotein expressed by the majority of the leukocytes (Somers et al., 2000).

The selectin-mediated process of leukocyte rolling along the endothelium is of utmost importance for cellular immune response. The antiadhesive properties of sulfated polysaccharides such as fucoidans and heparin, along with semi-synthetic derivatives of glucans, have been described using in vitro and in vivo models, disclosing their potential for the development of new anti-inflammatory drugs (Fritzsche et al., 2006; Ludwig et al., 2006; Cumashi et al., 2007). Some heparin derivatives have been subjected to clinical trials (Elsayed and Becker, 2003), and the P-selectin-blocking activity may account for the anti-inflammatory effect of these compounds (Nelson et al., 1993). However, heparin has been shown to present several in vivo effects as a result of its complex and variable composition, justifying the search for new sources of sulfated polysaccharides with potential anti-inflammatory activity (Fritzsche et al., 2006). Therefore, the aim of the present work was to characterize the chemical composition of some polysaccharide-rich fractions of Lithothamnion muelleri Lenormand ex Rosanoff (Hapalidiaceae) and to evaluate their antiadhesive properties using an in vivo model.

\section{Material and Methods}

\section{Algal material}

The algal material was donated by the company Phoster Algamar, Belo Horizonte, Brazil, and was furnished as a whitish granulate $(4 \mathrm{~kg})$ named "concentrado mineral marinho" (marine mineral concentrate). According to the company, the alga was washed sequentially with tap water and distilled water to remove salt and all visible epiphytes. In the sequence, it was ground in a ball mill and dried in a ventilated oven to afford the granulate. The species was identified by Dr. Maria Carolina M. de O. Henriques, Instituto Biodiversidade Marinha, Rio de Janeiro, Brazil.

\section{Extraction of polysaccharides}

Several extraction conditions were tested to improve the polysaccharide yields. Portions of the granulate were submitted to extraction with water at different temperatures $(40,60,70,80$, and $100{ }^{\circ} \mathrm{C}$ ) for $6 \mathrm{~h}$ under mechanical stirring, using the proportion of $5 \%,(\mathrm{w} / \mathrm{v})$ granulate in distilled water. The residue remaining after water extraction at $60{ }^{\circ} \mathrm{C}$ was recovered by vacuum filtration over paper and was re-extracted sequentially with $1 \%$ and $2 \%(\mathrm{w} / \mathrm{v}) \mathrm{Na}_{2} \mathrm{CO}_{3}$ solution for $2 \mathrm{~h}$ at $60{ }^{\circ} \mathrm{C}$, using the same proportion of algal material/solvent extractor $(5 \%, w / v)$, which led to fractions B1 and B2, respectively. Additionally, another portion of the residue was submitted to extraction with $1 \mathrm{~m} \mathrm{HCl}$ for $2 \mathrm{~h}$ at $60^{\circ} \mathrm{C}$. The extracts were concentrated in a rotavapor to a tenth of the original volume, at a maximum temperature of $60^{\circ} \mathrm{C}$. In the sequence, ethanol was added to the concentrated extracts in a 4:1 ratio (ethanol/extract, $\mathrm{v} / \mathrm{v}$ ) for polysaccharide precipitation, following centrifugation at $3000 \mathrm{x} g$ for $10 \mathrm{~min}$. The obtained precipitates were suspended several times in ethanol, and the resulting suspension was centrifuged. Finally, the precipitates were dialyzed against water through a cellulose membrane (cut off $10,000 \mathrm{Da}$ ) for $2-3 \mathrm{~d}$, and water was removed using a centrifugal vacuum concentrator (Labconco Centrivap, Kansas City, USA). $0.1 \mathrm{~m} \mathrm{HCl}$ solution was employed to remove the residual carbonate in the alkaline extracts, the $\mathrm{pH}$ value being adjusted to neutrality with $0.1 \mathrm{M} \mathrm{NaOH}$ solution prior to dialysis.

\section{Quantification of carbohydrate, protein, uronic acid, and sulfate contents}

The total contents of carbohydrates, proteins, and uronic acid were determined spectrophotometrically, whereas sulfate concentrations were assayed by turbidimetry. In each case, a five- or six-point calibration curve was constructed in triplicate by plotting the absorbance data and concentrations of appropriate standard solutions. The curves were obtained on three different days and had their statistical equivalency evaluated by ANOVA. Each sample was analysed in triplicate, and the results are expressed as mean \pm standard deviation (SD).

The total carbohydrate content was determined by the phenol-sulfuric acid method (Dubois et al., 1956). Standard solutions of galactose 
$(0.1$ to $1.0 \mathrm{mg} / \mathrm{mL})$ were employed for constructing the calibration curves, with detection at $490 \mathrm{~nm}$. Uronic acid was quantified by the colorimetric method of Filisetti-Cozzi and Carpita (1991), using glucuronic acid standard solutions $(0.02$ to $0.09 \mathrm{mg} / \mathrm{mL})$ to construct the calibration curves. The protein content was determined according to the method of Bradford (1976), using Coomassie Brilliant Blue G-250. Crystalline bovine serum albumin was employed as the standard for building the calibration curves. The sulfate content was assayed by the method of Dodgson and Price (1962), using standard solutions of potassium sulfate $(0.2$ to $1.0 \mathrm{mg} / \mathrm{mL})$ to obtain the calibration curves.

\section{Thin layer chromatography (TLC) analysis of sugar composition}

A mixture of B1 and B2 $(10 \mathrm{mg})$ was submitted to hydrolysis with $2 \mathrm{~m}$ trifluoroacetic acid $(5 \mathrm{~mL})$ under reflux at $110{ }^{\circ} \mathrm{C}$ for $6 \mathrm{~h}$. The solution was concentrated for TLC analysis on cellulose-precoated aluminium sheets (Merck, Mannheim, Germany) with and without fluorescent indicator, employing $n$-butanol/ethyl acetate/pyridine/water (6:1:5:4, v/v) as eluent. The chromatograms were visualized under UV light (365 nm) after spraying with aniline/phthalic acid reagent followed by heating. Authentic samples of glucose, galactose, rhamnose, xylose, arabinose, and glucuronic acid were employed as reference compounds.

\section{Molecular weight determination}

The average molecular weight of the polysaccharide fractions was determined by high-performance gel permeation chromatography (HPGPC), using a Shimadzu HPLC system (Tokyo, Japan) composed of an LC-8A quaternary pump, an SCL-8A controller, a DID-6A refractive index detector, and a CR4A integrator. The analysis was performed at room temperature on a ultrahydrogel linear column $(300 \times 7.8 \mathrm{~mm}$ i.d.; Waters, Milford, USA), eluted with $0.1 \mathrm{~m} \mathrm{NaNO}_{3}$ solution, at a flow rate of $0.5 \mathrm{~mL} / \mathrm{min}$. A calibration curve was prepared by plotting the elution volume of known MW pullulan standards (P-5, P-10, P-20, P-50, P-100, P-200, P-400, P-800; Shodex Standard P-82; Sigma-Aldrich, St. Louis, USA) against the logarithm of their respective molecular weights. The analyses were performed in triplicate.

\section{Fractionation of polysaccharides}

The crude polysaccharide fraction B1 was fractionated by gel permeation chromatography. A portion of it $(130 \mathrm{mg})$ was applied to a Sephadex G-100 column $(45 \times 2 \mathrm{~cm}$ i.d. $)$ using water as eluent. Fractions of $5 \mathrm{~mL}$ each were collected, and their total carbohydrate contents were determined by the phenol/ $\mathrm{H}_{2} \mathrm{SO}_{4}$ method (Dubois et al., 1956). The fractions were combined into three groups (B1a, B1b, and B1c) according to the elution profile. The fractions were concentrated to a residue in a centrifugal vacuum concentrator (Labconco Centrivap), at a maximum temperature of $50{ }^{\circ} \mathrm{C}$, affording the residues B1a $(30 \mathrm{mg})$, $\mathrm{B} 1 \mathrm{~b}(61 \mathrm{mg})$, and B1c $(5 \mathrm{mg})$. The process was repeated with an additional amount of B1 $(130 \mathrm{mg})$, resulting in a similar chromatographic profile. Additionally, a portion of B2 (150 mg) was submitted to fractionation under the same conditions, affording the residues B2a $(23 \mathrm{mg}), \mathrm{B} 2 \mathrm{~b}(45 \mathrm{mg})$, and B2c (40 mg).

\section{Animals}

Male C57BL/6J (8 weeks old) mice were used in this study ( $n=5 /$ group). For surgical procedures, mice were anaesthetized with a mixture of ketamine and xilazine and kept warm throughout the experiment. All the procedures were in accordance with the Guidelines of the Animal Care Committee of the Universidade Federal de Minas Gerais, and were approved under the protocol 051/11 (CETEA-UFMG).

\section{Inhibition of leukocyte rolling}

The mouse cremaster preparation was used to study the behaviour of leukocytes in the microcirculation and adjacent connective tissue, as previously described (Kanwar et al., 1997). Briefly, an incision was made in the scrotal skin to expose the left cremaster muscle, which was then carefully removed from the associated fascia. A lengthwise incision was made on the ventral surface of the cremaster muscle using a cautery. The testicle and the epididymis were separated from the underlying muscle and moved into the abdominal cavity. The muscle was then spread out over an optically clear viewing pedestal and was secured along the edges with 4-0 suture. The exposed tissue was superfused with warm bicarbonate-buffered saline ( $\mathrm{pH}$ 7.4). An intravital microscope (BX50F4; 
Olympus, Tokyo, Japan) with a $20 \times$ objective lens and a $10 \times$ eyepiece was used to examine the cremasteric microcirculation. A video camera (5100 HS; Panasonic, Tokyo, Japan) was used to project the images onto a monitor, and the images were recorded for playback analysis using a conventional videocassette recorder.

Single, unbranched cremasteric venules (25$40 \mu \mathrm{m}$ i.d.) were selected, and to minimize variability, the same section of cremasteric venule was observed throughout the experiment. Rolling leukocytes were defined as those cells moving at a velocity less than that of erythrocytes within a given vessel. The flux of rolling cells was measured as the number of rolling cells passing by a given point in the venule per minute.

For each experiment, lipopolysaccharides (LPS) from E. coli (B4:0111, $1 \mu \mathrm{g} / \mathrm{mice}$ ) in $0.2 \mathrm{~mL}$ of saline were given locally by subcutaneous (s.c.) injection beneath the right scrotal skin using a $30 \mathrm{G}$ needle, $1 \mathrm{~h}$ before exteriorization. After $1 \mathrm{~h}$, the left cremaster was prepared for the experiment, the rolling of leukocytes was assessed. After this, the fractions $\mathrm{B} 1 \mathrm{a}, \mathrm{B} 1 \mathrm{~b}$, and $\mathrm{B} 1 \mathrm{c}(10 \mathrm{mg} / \mathrm{kg}$ body weight) in $0.1 \mathrm{~mL}$ of sterile phosphate-buffered saline (PBS) were administered by intravenous (i.v.) injection, and the rolling of leukocytes was reassessed. Fucoidan $(10 \mathrm{mg} / \mathrm{kg}$ body weight; Sigma-Aldrich) in $0.1 \mathrm{~mL}$ of sterile PBS was employed as positive control. The control mice received PBS alone.

\section{Results and Discussion}

The water extraction of L. muelleri was carried out at different temperatures $\left(40\right.$ to $\left.100{ }^{\circ} \mathrm{C}\right)$, resulting in polysaccharide yields from $0.007 \%$ to $0.011 \%(\mathrm{w} / \mathrm{w})$, the highest value was found at $60{ }^{\circ} \mathrm{C}$. This temperature was then chosen for alga extraction. In order to increase the yield of polysaccharides, the residue remaining after water extraction was subjected to alkaline extraction. This strategy was based on the occurrence of sulfated polysaccharides in other Corallinaceae species, whose solubility is considerably improved in basic solutions. Therefore, L. muelleri was submitted to sequential extraction with $1 \%$ and $2 \%(\mathrm{w} / \mathrm{v}) \mathrm{Na}_{2} \mathrm{CO}_{3}$ solutions, affording fractions $\mathrm{B} 1$ and $\mathrm{B} 2$, respectively. The alkaline extraction substantially increased the yield of polysaccharides $(0.032 \%$ and $0.050 \% \mathrm{w} / \mathrm{w}$, respectively, for B1 and B2) in comparison to ex- traction with water $(0.011 \% \mathrm{w} / \mathrm{v})$. Extraction of the residue with $1 \mathrm{M} \mathrm{HCl}$ was also evaluated but resulted in lower polysaccharide yield $(0.005 \%)$. Therefore, we focused the study on the alkaline fractions B1 and B2.

IR analysis of fractions B1 and B2 suggested similar chemical compositions. The spectra registered for these fractions confirmed their polysaccharide constitution, disclosed by the intense stretching bands at $3280 \mathrm{~cm}^{-1}(v \mathrm{O}-\mathrm{H})$ and $1070 \mathrm{~cm}^{-1}$ ( $v$ C-O). Moreover, the presence of uronic acid was confirmed by the intense bands at $1630 \mathrm{~cm}^{-1}$ and $1560 \mathrm{~cm}^{-1}$, respectively, assigned to carboxylic acid and carboxylate stretching vibrations. On its turn, the sulfated nature of the polysaccharide constituents of $\mathrm{B} 1$ and $\mathrm{B} 2$ was pointed out by the vibration bands of $\mathrm{S}=\mathrm{O}$ asymmetric and symmetric stretchings, respectively, at $1398 \mathrm{~cm}^{-1}$ and $1235 \mathrm{~cm}^{-1}$.

The chromatograms obtained for B1 and B2 by HPGPC revealed similar profiles, with three partially superimposed bands (data not shown). The chemical analysis of these fractions suggested related compositions, with nearly similar contents of total carbohydrates $[(40.0 \pm 1.0) \%$ and $(38.8 \pm 0.9) \%$, respectively, for B1 and B2] and uronic acid $[(4.5 \pm 0.1) \%$ and $(4.6 \pm 0.1) \%]$, but differences in the contents of sulfate $[(3.6 \pm 0.9) \%$ and $(18.0 \pm 1.0) \%]$ and total proteins $[(6.0 \pm 1.0) \%$ and $(2.3 \pm 0.1) \%]$.

The sugar composition of the polysacchariderich fractions was evaluated by TLC analysis of the hydrolysis products from a mixture of B1 and B2. These samples were employed in view of the similar composition of both fractions. The spots obtained in the chromatograms indicated the presence of galactose, xylose, and glucuronic acid. Fractionation of B1 and B2 by gel permeation chromatography afforded three groups of fractions each, which were combined based on their UV absorbance at $490 \mathrm{~nm}$ after the phenol/ $\mathrm{H}_{2} \mathrm{SO}_{4}$ reaction (Fig. 1). In order to obtain additional amounts of samples for the biological assay, the fractionation process was repeated with another portion of B1, resulting in a similar chromatogram (data not shown).

The chemical compositions of the fractions derived from $\mathrm{B} 1$ (B1a, B1b, and $\mathrm{B} 1 \mathrm{c})$ and $\mathrm{B} 2$ (B2a, B2b, and B2c) were analysed by spectrophotometric methods (Table I); the molecular weights were estimated by HPGPC. Fractions $\mathrm{B} 1 \mathrm{a}$ and B1b were constituted of polysaccha- 

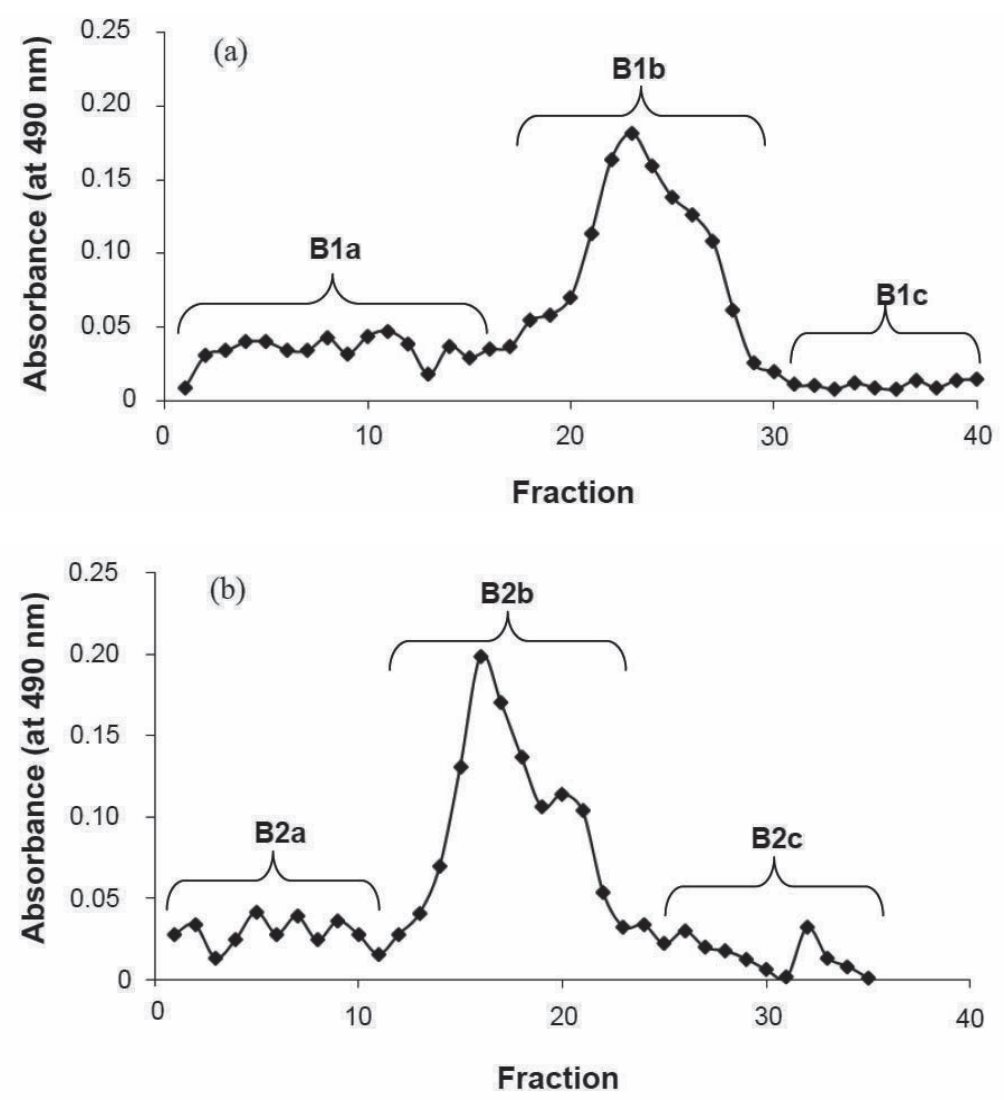

Fig. 1. Fractionation of (a) B1 and (b) B2 by gel permeation chromatography on a Sephadex G-100 column eluted with water. The chromatograms were constructed based on the absorbance at $490 \mathrm{~nm}$, after reaction with phenol/ sulfuric acid.

rides with similar contents of total carbohydrates $(46-48 \%)$, proteins $(12-14 \%)$, uronic acid $(7.0-7.4 \%)$, and sulfate $(21-25 \%)$, with approximate molecular massess of 180 to $230 \mathrm{kDa}$. On the other hand, the polysaccharides found in B1c had a lower molecular mass $(50 \mathrm{kDa})$ and distinct contents of carbohydrates $(6 \%)$ and uronic acid $(1.4 \%)$, but nearly similar contents of proteins $(11 \%)$ and sulfate $(19 \%)$. The fractionation of B2 afforded three groups of fractions with marked differences in their chemical compositions (Table I). A noticeable feature was the high content of protein found in B2a (32\%). In general, B1 fractions presented contents of uronic acid and molecular massess similar to those found in B2 fractions.

The high sulfate contents found in the polysaccharides of L. muelleri fell within the contents reported for the constituents of Corallina pilulifera (Usov et al., 1997). Other Corallinaceae species like Corallina officinalis, Bossiella orbigniana, Jania rubens, and Lithothamnion heterocladum have been described to possess polysaccharides with reduced contents of sulfate $(\sim 7-11 \%)$ and lower molecular masses $(\sim 10-33 \mathrm{kDa})$, but protein contents similar to those found here for L. muelleri (Navarro and Stortz, 2002; Navarro et al., 2011).

The antiadhesive activity of the polysaccharide fractions $\mathrm{B} 1 \mathrm{a}, \mathrm{B} 1 \mathrm{~b}$, and $\mathrm{B} 1 \mathrm{c}$ was assayed in a model of leukocyte rolling inhibition, employing intravital microscopy in mice. Fucoidan and PBS were used as positive and negative controls, respectively. The intravenous injection of fractions $\mathrm{B} 1 \mathrm{a}$ and $\mathrm{B} 1 \mathrm{c}$ in mice, at the dose of $10 \mathrm{mg} / \mathrm{kg}$ body weight, reduced leukocyte rolling by $83 \%$ 
Table I. Chemical composition of the polysaccharide-rich fractions of L. muelleri.

\begin{tabular}{lcccccc}
\hline Analysed & \multicolumn{5}{c}{ Composition $(\% \text { w/w })^{\mathrm{a}}$} \\
\cline { 2 - 7 } parameters & $\mathrm{B} 1 \mathrm{a}$ & $\mathrm{B} 1 \mathrm{~b}$ & $\mathrm{~B} 1 \mathrm{c}$ & $\mathrm{B} 2 \mathrm{a}$ & $\mathrm{B} 2 \mathrm{~b}$ & $\mathrm{~B} 2 \mathrm{c}$ \\
\hline Yield (\%) & 0.007 & 0.015 & 0.001 & 0.008 & 0.015 & 0.013 \\
Carbohydrates & $48 \pm 1$ & $46 \pm 5$ & $6 \pm 1$ & $34 \pm 2$ & $51 \pm 2$ & $10.5 \pm 0.8$ \\
Proteins & $14 \pm 3$ & $12 \pm 4$ & $11 \pm 3$ & $32 \pm 1$ & $14 \pm 2$ & $3 \pm 1$ \\
Uronic acid & $7 \pm 1$ & $7.4 \pm 0.3$ & $1.4 \pm 0.1$ & $9 \pm 1$ & $6 \pm 1$ & $1.7 \pm 0.1$ \\
Sulfate & $25 \pm 3$ & $21 \pm 1$ & $19 \pm 3$ & $9 \pm 2$ & $18 \pm 3$ & $3 \pm 1$ \\
Degree of sulfatation & 0.52 & 0.46 & 3.2 & 0.26 & 0.35 & 0.28 \\
Mol. weight (kDa) & $230 \pm 30$ & $180 \pm 50$ & $50 \pm 10$ & $270 \pm 20$ & $180 \pm 30$ & $70 \pm 10$ \\
\hline
\end{tabular}

${ }^{\mathrm{a}}$ Mean $\pm \mathrm{SD} ; n=3$.

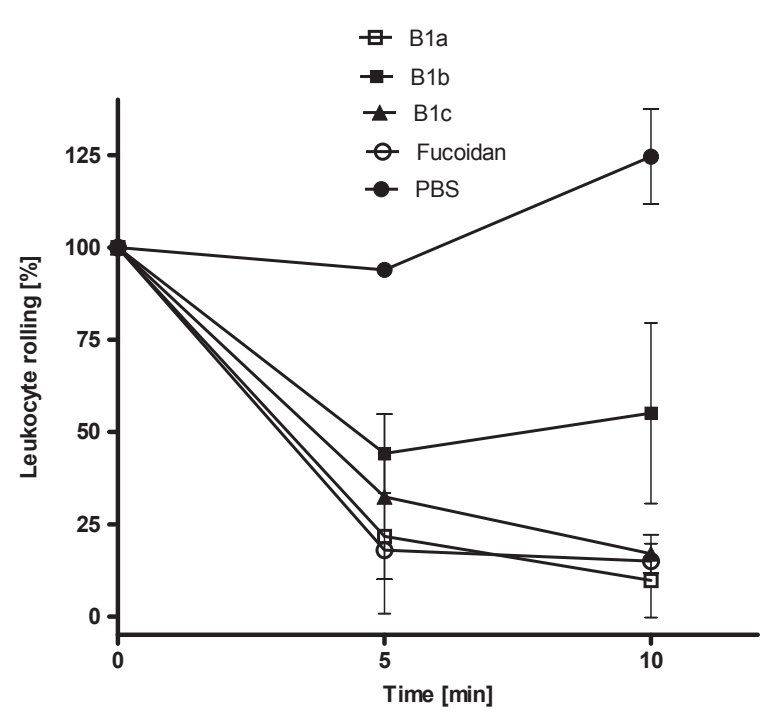

Fig. 2. In vivo inhibition of P-selectin-induced leukocyte rolling elicited by the polysaccharide-rich fractions of $L$. muelleri. Values are expressed as percentage of rolling (mean $\pm \mathrm{SD} ; n=3$ ) related to maximum rolling. Fractions were assayed at the dose of $10 \mathrm{mg} / \mathrm{kg}$ body weight; saline was employed as control.

and $90 \%$, respectively, after $10 \mathrm{~min}$ of administration (Fig. 2), whereas fucoidan (10 mg/kg body weight) induced a similar response. Although the polysaccharides found in $\mathrm{B} 1 \mathrm{a}$ and $\mathrm{B} 1 \mathrm{~b}$ fractions have a similar chemical composition (Table I), they induced different biological responses suggesting distinctive distribution of the substituent groups in the molecules.

Previous studies disclosed some structural features in sulfated polysaccharides that may affect rolling inhibition. According to Fritzsche et al. (2006), charge density is the most impor- tant parameter for P-selectin binding, whereas molecular weight is of minor relevance, and glycosidic backbone linkage holds certain importance. Hence, the potent activity exhibited by the B1c fraction could be explained by its high degree of sulfatation (DS = 3.2) in comparison to B1a (DS $=0.52)$ and B1b (DS = 0.46). A high degree of sulfatation is required for effective rolling inhibition, but low DS values can be balanced by high molecular weight (Fritzsche et al., 2006). This could explain the potent biological response induced by $\mathrm{B} 1 \mathrm{a}(\mathrm{MW} 230 \mathrm{kDa})$, despite of its reduced degree of sulfatation (DS = 0.52 ). The anionic density induced by the uronic acid moieties of polysaccharides from L. muelleri does not seem to be an important attribute for rolling inhibition. This inference is derived from the fact that B1c elicited a more potent inhibition than B1b, although it has a lower content of uronic acid $(1.4 \%$ and $7.4 \%$, respectively, for $\mathrm{B} 1 \mathrm{c}$ and $\mathrm{B} 1 \mathrm{~b})$.

In conclusion, the sulfated polysaccharides of L. muelleri induce significant leukocyte rolling inhibition and deserve further evaluation as potential templates for the development of new antiinflammatory agents.

\section{Acknowledgements}

The authors are thankful to $\mathrm{CNPq} / \mathrm{Bra}-$ zil (Conselho Nacional de Desenvolvimento Científico e Tecnológico) for financial support and research fellowships and to CAPES/Brazil (Coordenação de Aperfeiçoamento de Pessoal de Nível Superior, Brazil) for MSc fellowships (to C.M.S. and B.G.M.). The company Phoster Algamar is acknowledged for furnishing the algal material. 
Aslam M. N., Bhagavathula N., Paruchuri T., Hu X., Chakrabarty S., and Varani J. (2009), Growth-inhibitory effects of a mineralized extract from the red marine algae, Lithothamnion calcareum, on $\mathrm{Ca}^{2+}-$ sensitive and $\mathrm{Ca}^{2+}$-resistant human colon carcinoma cells. Cancer Lett. 283, 186-192.

Aslam M. N., Paruchuri T., Bhagavathula N., and Varani J. (2010a), A mineral-rich red algae extract inhibits polyp formation and inflammation in the gastrointestinal tract of mice on a high-fat diet. Integr. Cancer Ther. 9, 93-99.

Aslam M. N., Kreider J. M., Paruchuri T., Bhagavathula N., Da Silva M., Zernicke R. F., Goldstein S. A., and Varani J. (2010b), A mineral-rich extract from the red marine algae Lithothamnion calcareum preserves bone structure and function in female mice on a Western-style diet. Calcif. Tissue Int. 86, 313-324.

Bilan M. I. and Usov A. I. (2001), Polysaccharides of calcareous algae and their effect on the calcification process. Russ. J. Bioorg. Chem. 27, 2-16.

Bradford M. M. (1976), A rapid and sensitive method for the quantitation of microgram quantities of protein utilizing the principle of protein-dye binding. Anal. Biochem. 72, 248-254.

Cumashi A., Ushakova N. A., Preobrazhenskaya M. E., D'Incecco A., Piccoli A., Totani L., Tinari N., Morozevich G. E., Berman A. E., Bilan M. I., Usov A. I., Ustyuzhanina N. E., Grachev A. A., Sanderson C. J., Kelly M., Rabinovich G. A., Iacobelli S., and Nifantieva N. E. (2007), A comparative study of the anti-inflammatory, anticoagulant, antiangiogenic, and antiadhesive activities of nine different fucoidans from brown seaweeds. Glycobiology 17, 541-552.

Dame M. K., Veerapaneni I., Bhagavathula N., Naik M., and Varani J. (2011), Human colon tissue in organ culture: calcium and multi-mineral-induced mucosal differentiation. In Vitro Cell Dev. Biol. Anim. 47, $32-38$.

Dodgson K. S. and Price R. G. (1962), A note on the determination of the ester sulphate content of sulphated polysaccharides. Biochem. J. 84, 106-110.

Dubois M., Gilles K. A., Hamilton J. K., Rebers P. A., and Smith F. (1956), Colorimetric method for determination of sugar and related substances. Anal. Chem. 28, 350-356.

Elsayed E. and Becker R. C. (2003), The impact of heparin compounds in cellular inflammatory responses: a construct for future investigations and pharmaceutical developments. J. Thromb. Thrombolysis 15, 11-18.
Filisetti-Cozzi T. M. C. C. and Carpita N. C. (1991), Measurement of uronic acids without interference from neutral sugars. Anal. Biochem. 197, 157-162.

Fritzsche J., Alban S., Ludwig R. J., Rubant S., Boehncke W., Schumacher G., and Bendas G. (2006), The influence of various structural parameters of semisynthetic sulfated polysaccharides on the $\mathrm{P}$ selectin inhibitory capacity. Biochem. Pharmacol. 72, $474-485$.

Hong I. H., Ji H., Hwa S. Y., Jeong W. I., Jeong D. H., Do S. H., Kim J. M., Ki M. R., Park J. K., Goo M. J., Hwang O. K., Hong K. S., Han J. Y., Chung H. Y., and Jeong K. S. (2011), The protective effect of ENA actimineral resource $\mathrm{A}$ on $\mathrm{CCl}_{4}$-induced liver injury in rats. Mar. Biotechnol. 13, 462-473.

Kanwar S., Bullard D. C., Hickey M. J., Smith C. W., Beaudet A. L., Wolitzky B. A., and Kubes P. (1997), The association between alpha4-integrin, P-selectin, and E-selectin in an allergic model of inflammation. J. Exp. Med. 185, 1077-1087.

Ludwig R. J., Alban S., and Boehncke W. H. (2006), Structural requirements of heparin and related molecules to exert a multitude of anti-inflammatory activities. Mini Rev. Med. Chem. 6, 1009-1023.

Navarro D. A. and Stortz C. A. (2002), Isolation of xylogalactans from the Corallinales: influence of the extraction method on yields and compositions. Carbohydr. Polym. 49, 57-62.

Navarro D. A., Ricci A. M., Rodriguez M. C., and Stortz C. A. (2011), Xylogalactans from Lithothamnion heterocladum, a crustose member of the Corallinales (Rhodophyta). Carbohydr. Polym. 84, 944-951.

Nelson R. M., Cecconi O., Roberts W. G., Aruffo A., Linhardt R. J., and Bevilacqua M. P. (1993), Heparin oligosaccharides bind L- and P-selectin and inhibit acute inflammation. Blood 82, 3253-3258.

Ryan S., O'Gorman D. M., and Nolan Y. M. (2011), Evidence that the marine-derived multi-mineral aquamin has anti-inflammatory effects on cortical glialenriched cultures. Phytother. Res. 25, 765-767.

Somers W. S., Tang J., Shaw G. D., and Camphausen R. T. (2000), Insights into the molecular basis of leukocyte tethering and rolling revealed by structures of $\mathrm{P}$ - and E-selectin bound to SLe(X) and PSGL-1. Cell 103, 467-479.

Usov A. I., Bilan M. I., and Shashkov A. S. (1997), Structure of a sulfated xylogalactan from the calcareous red alga Corallina pilulifera $\mathrm{P}$. et R. (Rhodophyta, Corallinaceae). Carbohydr. Res. 303, 93-102. 